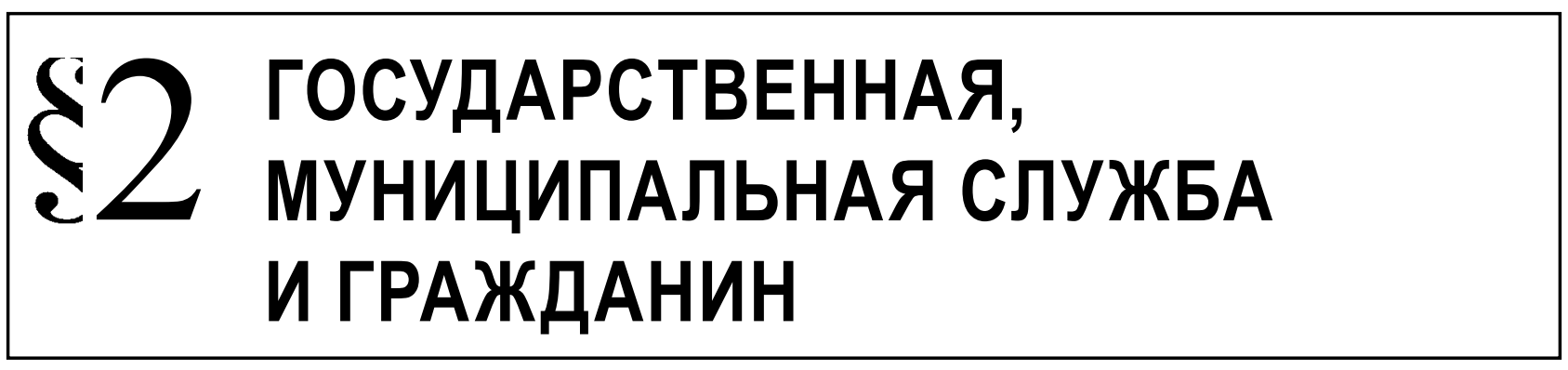

Курганов Н.А.

\title{
МУНИЦИПАЛЬНАЯ СЛУЖБА В РОССИИ: ПРОБЛЕМЫ ТЕОРИИ И ОРГАНИЗАЦИИ
}

\begin{abstract}
Аннотация. Объект исследования - общественные отношения, связанные с организацией и прохождением муниципальной службы Российской Федерации. Предметом исследования являются понятие и границы муниципальной службы в Российской Федерации. Автор подробно рассматривает такие аспекты темы как международная практика регулирования служебной деятельности, развитие законодательства о государственной и муниципальной службах в Российское федерации. Особое внимание уделяется институту должностей на муниципальной службе. На основе полученных данных, сформулированы конкретные предложения по улучшению действующих нормативных правовых актов. Методологическую базу исследования составляет комплекс общенаучных и специальных методов познания: системный, социологический, сравнительноправовой, метод перехода от абстрактного к конкретному, от общего к частному. На основе проведенного исследования автор обращает внимание на проблемные аспекты муниципальной службы на современном этапе ее развития. Сформулированы предложения по совершенствованию теоретико-правовых и организационных основ муниципальной службы в России, в частности, предложено выделить особую категорию должностей в муниципальных органах власти - должностей, замещение которых связано с коррупционными рисками - установив для данной категории специальный правовой статус.

Ключевые слова: муниципальная служба, служебная деятельность, должность муниципальной службы, муниципальный служащий, классификация муниципальных служащих, должностное лицо, коррупционные риски, местное самоуправление, муниципальные учреждения, реестр должностей.

Review. The object of the research is a range of social relations in the sphere of organization and service in municipal bodies of the Russian Federation. The subject of the research is the definition and the limits of municipal service in the Russian Federation. The author studies the issues of international practice of service regulation, development of the legislation about public and municipal service in the Russian Federation. Special attention is paid to the institution of positions on municipal service. On the base of the empirical data the author formulates the suggestions about the enhancement of the existing legal acts. The methodology of the research is based on the complex of the general scientific and the special methods of cognition: the systems method, the sociological and comparative-legal methods, the methods of shift from the abstract to the concrete and from the general to the specific. In the result of the research the author outlines the problem aspects of municipal service at the recent stage of development. The author suggests the ways of theoretical-legal and organizational grounds of municipal service in Russia enhancement, particularly, it is offered to institute a special category of positions in municipal authorities - the positions prone to corruption risks - establishing a special legal status for this category.

Keywords: official, classification of municipal officials, municipal official, position of municipal service, service, municipal service, corruption risks, local government, municipal bodies, positions register.
\end{abstract}

$\mathrm{M}$ униципальная служба - один из видов служебной деятельности. В отечественной литературе, начиная с 90-х годов XX века, к разновидностям служебной деятельности традиционно относят различные виды государственной службы (военную службу, службу в правоохранительных органах и гражданскую службу), муниципальную службу, а также службу в государственных предприятиях и учреждениях, в международных и иностранных организациях, в общественных объединениях и в частных организациях [13, с. 15-19]. 
Отдельные виды служебной деятельности обладают как схожими чертами, так и различиями. В юридической науке весьма широкое распространение получила идея о целесообразности создания единой правовой базы, устанавливающей общие принципы организации и функционирования государственной и муниципальной служб $[6$, с. 3334]. По мнению Н.М. Антоновой, государственная и муниципальная служба уже сегодня официально рассматриваются в Российской Федерации в определенном единстве и взаимосвязи [4, с. 4-5].

Международная практика регулирования служебной деятельности, как правило, развивается по пути унификации государственной и муниципальной служб. Так, в международном праве получил широкое распространение термин «публичное должностное лицо», который согласно Конвенции ООН, против коррупции 2003 г. включает:

- назначаемых или избираемых лиц, занимающих какую-либо должность в законодательном, исполнительном, административном или судебном органе на постоянной, или временной основе, за плату или без оплаты труда, независимо от уровня должности этого лица;

- лиц, выполняющих какую-либо публичную функцию (в том числе для публичного ведомства или публичного предприятия, или предоставляющих какую-либо публичную услугу) [12].

В Европейской хартии местного самоуправления определение муниципальной службы отсутствует, однако из толкования ст. 6 можно выяснить, что муниципальный служащий обозначается как local government employees. "Англо-русский экономический словарь» (ABBYY lingvo) дает точно такой же перевод и указывает синонимичным словосочетание public employee [3]. Интересным является тот факт, что тот же самый словарь переводит public employee и как муниципальный служащий, и как государственный служащий. Так же в заключении следует сказать, что само слово public можно перевести как общественный, а слово employeе означает наемный рабочий. Статья 6 Хартии не проводит разделения между лицами, занимающимися решением вопросов местного самоуправления на государственных служащих и муниципальных служащих, а скорее относит их к категории наемных служащих по решению общественных вопросов в локальных правительствах [8].

В Российской Федерации, начиная с 1990-х годов, законодательство о государственной и муниципальной службах развивалось автономно. Первым нормативным правовым актом федерального уровня, в котором законодателем было сформулировано определение понятия «муниципальная служба», стал закон «Об общих принципах организации местного самоуправления в Российской Федерации» 1995 года. В первой статье данного закона под муниципальной службой понималась «профессиональная деятельность на постоянной основе в органах местного самоуправления по исполнению их полномочий» [19]. Следует отметить, что указанное определение муниципальной службы имело весьма существенные отличия по сравнению с определением государственной службы, сформулированном в принятом практически одновременно законе «Об основах государственной службы Российской Федерации» [20]. Законодателем в 1995 году к государственной службе была отнесена лишь деятельность «по обеспечению исполнения полномочий государственных органов», осуществляемая лицами, замещающими должности категорий «Б» и «В». Вместе с тем, в число должностей категорий «Б» и «В» были включены, например, должности инспектора, заместителя министра, руководителя федеральной службы. Лица, замещающие данные должности, обладали статусом должностного лица и были наделены правомочиями по самостоятельной реализации компетенции государственного органа. Данные обстоятельства, по мнению отдельных авторов, свидетельствовали о том, что фактически государственная служба включала в себя деятельность не только по обеспечению исполнения полномочий государственных органов, но и по их непосредственному исполнению [1, с. 11].

Согласно Федеральному закону 1998 года «Об основах муниципальной службы в Российской Федерации» - первому законодательному акту федерального уровня, специально посвященному вопросам организации и прохождения муниципальной службы - к муниципальной службе была отнесена лишь профессиональная деятельность, осуществляемая на постоянной основе, на невыборных муниципальных должностях [22]. Тем самым законодателем из числа муниципальных служащих были исключены лица, замещающие выборные муниципальные должности, что по мнению многих ученых-правоведов, было ошибочным решением законодателя [2, с. 22].

В соответствии с действующим Федеральным законом от 2 марта 2007 г. № 25-Ф3 «0 муниципальной службе в Российской Федерации» (далее Закон о муниципальной службе), муниципальная служба - профессиональная деятельность граждан, осуществляемая на постоянной основе на должностях муниципальной службы, замещаемых путем заключения трудового договора (контрак- 
та) [18]. Аналогичные определения содержатся в законах о муниципальной службе ряда субъектов ЮФО - Астраханской, Ростовской областей, Краснодарского края и Республики Адыгея.

Таким образом, анализ действующих федеральных, региональных и муниципальных правовых актов показывает, что законодатель не отказался от узкого подхода к пониманию сущности муниципальной службы. Законодатель не относит к муниципальной службе деятельность по прямому (непосредственному) исполнению полномочий органов местного самоуправления. То есть, должностные лица муниципальных органов, замещающие выборные должности (в отдельных случаях и иные должности, например, должности председателя контрольно-счетного органа муниципального образования или члена избирательной комиссии муниципального образования), не являются муниципальными служащими.

Таким образом, законодатель рассматривает муниципальную службу как профессиональную деятельность лишь на некоторых должностях в органах местного самоуправления. Во-первых, должности, создаваемые в целях технического обеспечения деятельности органов местного самоуправления, не отнесены к должностям муниципальной службы. Во-вторых, действующее законодательство разделяет два понятия: «должность муниципальной службы» и «муниципальная должность». В соответствии со ст. 2 Федерального закона от 6 октября 2003 г. № 131-Ф3 «Об общих принципах организации местного самоуправления в Российской Федерации» (далее - Федеральный закон № 131-ФЗ) к муниципальным должностям отнесены должности депутатов, членов выборных органов местного самоуправления, выборные должностные лица местного самоуправления, члены избирательной комиссии муниципального образования [21].

Мы не согласны с подходом законодателя и считаем, что к муниципальной службе следует относить также лиц, замещающих выборные муниципальные должности, то есть тех, кто непосредственно исполняет полномочия органов местного самоуправления. Гражданин, после замещения должности в органе местного самоуправления, состоит в особой публично-правовой связи с муниципальным образованием, выступая агентом местной власти и осуществляя (в той или иной форме) полномочия органа местного самоуправления. Тем самым гражданин, замещающий должность в органе местного самоуправления, участвует на профессиональной основе в реализации функций местного самоуправления. Лица, замещающие выборные муниципальные должности, безусловно, соответствует всем вышеперечисленным признакам, следовательно, должны быть отнесены к муниципальным служащим.

По нашему мнению, под муниципальной службой следует понимать публично-правовую связь между гражданином, замещающим должность в органе местного самоуправления, и муниципальным образованием, в силу которой гражданин на профессиональной основе участвует в реализации функций местного самоуправления путем прямого или опосредованного исполнения полномочий органов местного самоуправления.

Несмотря на существенный рост числа государственных и муниципальных чиновников в первом десятилетии XXI века, эффективности государственного и муниципального управления не произошло.

По данным Росстата численность работников государственных органов и органов местного самоуправления, например, в ЮФО увеличилась с 71,3 тыс. человек в 2000 году до 109,2 тыс. человек в 2009 году [5]. Следует указать, что наметившееся, начиная с 2010 года, снижение числа муниципальных служащих не во всех случаях означает реальное уменьшение количества сотрудников, осуществляющих деятельность по обеспечению исполнения полномочий муниципальных органов. В последние годы получила распространение практика создания при органах местного самоуправления казенных муниципальных учреждений («исполнительных дирекций» и т.п.), сотрудниками которых становятся лица, ранее занимавшие должности муниципальной службы в органах местного самоуправления и переведенные в упомянутые выше учреждения [16]. Цели и виды деятельности создаваемых учреждений в той или иной степени совпадают с задачами и функциями различных структурных подразделений органов местного самоуправления.

Например, Постановлением администрации Волгограда от 30.08.2011 № 2488 создано муниципальное казенное учреждение «Материальнохозяйственная служба» с установленной штатной численностью работников в количестве 133 единицы (п. 3) [14]. В качестве основных целей деятельности данного учреждения определены: ведение бухгалтерского учета, материально-техническое, информационное обеспечение деятельности администрации Волгограда и ее отраслевых (функциональных) и территориальных подразделений.

Таким образом, сотрудники вновь образованных муниципальных учреждений утрачивают статус му- 
ниципальных служащих, при этом должностные обязанности у них, как правило, остаются прежними, так как цели и виды деятельности создаваемых учреждений совпадают с прежними функциями конкретных отделов органов местного самоуправления.

Действующее законодательство и правоприменительная практика, складывающаяся в органах местного самоуправления, позволяют достаточно легко манипулировать численностью муниципальных служащих. Нечеткость границ муниципальной службы обусловлена как отсутствием объективных критериев отграничения должностей муниципальной службы, с одной стороны, от должностей технического персонала в органе местного самоуправления, так и возможностью передачи ряда функций муниципального органа казенным учреждениям.

Согласно действующему Закону о муниципальной службе замещение должности муниципальной службы выступает ведущим критерием, позволяющим относить тех или иных лиц к муниципальным служащим [9, с. 20]. При этом ключевым понятием для российской государственной и муниципальной службы является должность [7, с. 275]. Таким образом, должность муниципальной службы является основным элементом организации муниципальной службы в Российской Федерации.

Статьей 6 Закона о муниципальной службе определено понятие должности муниципальной службы. В соответствии с положениями названной статьи должность муниципальной службы обладает тремя основополагающими характеристиками, связывающими ее с понятием местного самоуправления: 1) должность учреждается именно в органе местного самоуправления, ее наименование должно отражать специфику и функциональное предназначение этого органа; 2) образование должности обусловлено указанием на это в уставе муниципального образования; 3) должность находится в прямой связи с перечнем обязанностей по исполнению полномочий муниципального органа.

Закон о муниципальной службе указывает только на общие черты классификации должностей: градацию на пять групп должностей и функциональное деление (обеспечение исполнения полномочий муниципальных органов и обеспечение исполнения полномочий лиц, замещающих муниципальные должности).

Анализ норм главы 2 Закона о муниципальной службе указывает на то, что федеральный законодатель, отказался от деления должностей муниципальной службы на категории, в отличие от подобного деления должностей государственной гражданской службы. Однако в реестрах должностей, принимаемых на муниципальном уровне, должности распределены, как правило, по категориям и группам с учетом типологии органов местного самоуправления, которая дана в Федеральном законе № 131-Ф3 [10, с. 56-60]. При этом одинаковые по своему функционалу должности в различных муниципальных образованиях не совпадают по категориям и группам, а муниципальные служащие, по сути занимающиеся обеспечительной деятельностью, могут замещать должности, относимые к более высокой группе и, соответственно, получать денежное вознаграждение в большем размере по сравнению с другими категориями служащих. По нашему мнению, эта ситуация отрицательно сказывается на процессе управления и приводит к нарушению прав муниципальных служащих на получение равной оплаты за равный труд, а также к необоснованным расходам местных бюджетов.

Решению указанных проблем может способствовать закрепление в федеральном законодательстве особой категории муниципальных должностей - должностей, замещение которых связано с коррупционными рисками - и, одновременно повышение уровня денежного содержания данной категории служащих по сравнению с лицами, осуществляющими функции по обеспечению деятельности органов местного самоуправления. Таким образом, все должности, учреждаемые в органах местного самоуправления, предлагается разделить на две категории: 1) должности, замещение которых связано с коррупционными рисками и 2) должности, замещение которых не связано с коррупционными рисками.

К первой категории должностей, на наш взгляд, следует относить должностных лиц и специалистов. При этом законодательство о муниципальной службе должно регулировать процесс прохождения службы только лицами, замещающими должности первой категории.

В научной литературе и законодательстве традиционно выделяют особую категорию муниципальных служащих - должностных лиц [9, с. 2021]. Основным отличительным признаком должностного лица местного самоуправления является наличие у него исполнительно-распорядительных полномочий по решению вопросов местного значения и (или) по организации деятельности органа местного самоуправления. Как уже было отмечено, в отличие от положений действующего Закона о муниципальной службе, мы исходим из целесообразности отнесения к муниципальным служащим тех, кто сегодня замещает муниципальные долж- 
ности. Таким образом, под должностными лицами в органах местного самоуправления следует понимать, во-первых, граждан, замещающих выборные должности, во-вторых, иных лиц, наделенных организационно-распорядительными или административно-хозяйственными полномочия

В первую категорию должностей - должностей, замещение которых связано с коррупционными рисками - представляется возможным также включать специалистов. Специалисты, как правило, непосредственно не участвуют в реализации функций муниципального управления. Однако, как указывает В.А. Юсупов, «они обеспечивают работу органа управления путем осуществления специальных функций. Задачей этого вида служащих является выработка проектов решений и предложений, направленных на более эффективное решение технических, экономических, организационных, социальных и других задач» [23]. В соответствии с разделом III Указа Президента РФ от 18 мая 2009 года № 557 к числу лиц, замещающих должности с коррупционными рисками, на- ряду с должностными лицами отнесены граждане, осуществляющие полномочия по предоставлению государственных услуг, по подготовке решений о распределении бюджетных ассигнований, субсидий, межбюджетных трансфертов [17].

Ко второй категории следует относить должности, учреждаемые в целях административно-хозяйственного, финансово-экономического, документационного, организационного, технического и иного обеспечения деятельности органов местного самоуправления. Официальное признание отсутствия коррупционных рисков в случае замещения той или иной должности означает, на наш взгляд, нецелесообразность установления для этой категории служащих запретов и ограничений. Следовательно, отсутствует необходимость в наличии особого публично-правового регулирования процесса прохождения службы, данной категорией сотрудников органов местного самоуправления. Правовое положение данной категории служащих - обеспечивающего персонала - должно быть определено в трудовом законодательстве.

\section{Библиография:}

1. Абезин Д.А. Правовое регулирование государственной службы субъектов РФ: автореф. дис.к.юрид.н. Волгоград, 2003. 24 c.

2. Абезин Д.А., Михнева С.В. Правовое регулирование деятельности и юридическое положение государственных и муниципальных служащих в Российской Федерации: региональный аспект: монография. Волгоград: Изд-во ГоУ ВПО «ВАГС», 2005. 251 с.

3. Англо-русский экономический словарь ABBYY Lingvo-Online [Электронный ресурс].-Режим доступа: http://www. lingvo-online.ru/ru/LingvoDictionaries/Details?dictionary=LingvoEconomics+(En-Ru)

4. Антонова Н.М. Конституционно-правовой статус публичных служащих в Российской Федерации: автореф. дис.к.юрид.н. М, 2012. 26 с.

5. База данных численности работников государственных органов и органов местного самоуправления. Официальный сайт Федеральной службы государственной статистики [Электронный ресурс].-Режим доступа: http:// www.gks.ru/wps/wcm/connect/rosstat_main/rosstat/ru/statistics/state/

6. Братановский С.Н., Епифанов А.Е., Глейкин В.А. Проблемы совершенствования муниципальной службы в России. Саратов: Наука, 2008. 189 с.

7. Гусев А.В. Реформа законодательства о муниципальной службе. // Научный ежегодник Института философии и права УрО РАН, 2007. №7. С. 273-284.

8. Европейская хартия местного самоуправления ЕТS № 122 // СЗ РФ. 1998. № 36. Ст. 4466.

9. Киреева Е.Ю. Правовой статус муниципальных служащих в Российской Федерации: монография. М.: Изд-во РАГС, 2008. 182 c.

10. Кожевников О.А. О реестре должностей муниципальной службы в субъекте РФ. // Российский юридический журнал. № 1. 2010. С. 56-60.

11. Козбаненко В.А. Правовое обеспечение статуса государственных и муниципальных служащих: общее и особенное. //Государство и право. № 1. 2003. С. 13-24.

12. Конвенция Организации Объединенных Наций против коррупции (принята в г. Нью-Йорке 31.10 .2003 Резолюцией 58/4 на 51-ом пленарном заседании 58-ой сессии Генеральной Ассамблеи ООН) // СЗ РФ. 2006. № 26. Ст. 2780

13. Манохин В.М. Служба и служащий в Российской Федерации: правовое регулирование. М.: Юрист, 1997. 294 с.

14. Постановление администрации Волгограда от 30 августа 2011 г. № 2488 «О создании муниципального казенного учреждения «Материально-хозяйственная служба» [Электронный ресурс].-Режим доступа: Справочно-правовая система «КонсультантПлюс».

15. Старилов Ю.Н. Служебное право. М.: БЕК, 1996. 683 с.

16. Отделы администрации Волгограда. Официальный сайт администрации Волгограда [Электронный ресурс].Режим доступа: http: // www.volgadmin.ru/ru/MPAuthority/Otdel.aspx

17. Указ Президента РФ от 18 мая 2009 г. № 557 «Об утверждении перечня должностей федеральной государственной службы, при назначении на которые граждане и при замещении которых федеральные государственные 
служащие обязаны представлять сведения о своих доходах, об имуществе и обязательствах имущественного характера, а также сведения о доходах, об имуществе и обязательствах имущественного характера своих супруги (супруга) и несовершеннолетних детей» // СЗ РФ. 2009. № 21. Ст. 2542.

18. Федеральный закон от 2 марта 2007 г. № 25-Ф3 «О муниципальной службе в Российской Федерации» // СЗ РФ. 2007. № 10. Ст. 1152.

19. Федеральный закон от 28 августа 1995 года № 154-Ф3 «Об общих принципах организации местного самоуправления в Российской Федерации» (утратил силу) // СЗ РФ. 1995. № 35. Ст. 3506.

20. Феделральный закон от 31 июля 1995 года № 119-ФЗ «Об основах государственной службы Российской Федерации» (утратил силу) // СЗ РФ. 1995. № 31. Ст. 2990.

21. Федеральный закон от 6 октября 2003 г. № 131-Ф3 «Об общих принципах организации местного самоуправления в РФ» // СЗ РФ. 2003. № 40. Ст. 3822.

22. Федеральный закон от 8 января 1998 г. № 8-ФЗ «Об основах муниципальной службы в Российской Федерации» (утратил силу) // СЗ РФ. 1998. № 2. Ст. 224.

23. Юсупов В.А. Научная организация исполнительной власти. Волгоград. Изд-во Волгогр. ин-та экономики, социологии и права, 1998. 147 с.

\section{References (transliterated):}

1. Abezin D.A. Pravovoe regulirovanie gosudarstvennoi sluzhby sub"ektov RF: avtoref. dis.k.yurid.n. Volgograd, 2003. 24 s.

2. Abezin D.A., Mikhneva S.V. Pravovoe regulirovanie deyatel'nosti i yuridicheskoe polozhenie gosudarstvennykh i munitsipal'nykh sluzhashchikh v Rossiiskoi Federatsii: regional'nyi aspekt: monografiya. Volgograd: Izd-vo GOU VPO «VAGS», 2005. $251 \mathrm{~s}$.

3. Anglo-russkii ekonomicheskii slovar' ABBYY Lingvo-Online [Elektronnyi resurs].-Rezhim dostupa: http://www.lingvoonline.ru/ru/LingvoDictionaries/Details?dictionary=LingvoEconomics $+(\mathrm{En}-\mathrm{Ru})$

4. Antonova N.M. Konstitutsionno-pravovoi status publichnykh sluzhashchikh v Rossiiskoi Federatsii: avtoref. dis.k.yurid.n. M, 2012.26 s.

5. Baza dannykh chislennosti rabotnikov gosudarstvennykh organov i organov mestnogo samoupravleniya. Ofitsial'nyi sait Federal'noi sluzhby gosudarstvennoi statistiki [Elektronnyi resurs].-Rezhim dostupa: http://www.gks.ru/wps/wcm/ connect/rosstat_main/rosstat/ru/statistics/state/

6. Bratanovskii S.N., Epifanov A.E., Gleikin V.A. Problemy sovershenstvovaniya munitsipal'noi sluzhby v Rossii. Saratov: Nauka, 2008. 189 s.

7. Gusev A.V. Reforma zakonodatel'stva o munitsipal'noi sluzhbe. // Nauchnyi ezhegodnik Instituta filosofii i prava UrO RAN, 2007. №7. S. 273-284.

8. Evropeiskaya khartiya mestnogo samoupravleniya ETS № 122 // SZ RF. 1998. № 36. St. 4466.

9. Kireeva E.Yu. Pravovoi status munitsipal'nykh sluzhashchikh v Rossiiskoi Federatsii: monografiya. M.: Izd-vo RAGS, 2008.182 s.

10. Kozhevnikov O.A. O reestre dolzhnostei munitsipal'noi sluzhby v sub"ekte RF. // Rossiiskii yuridicheskii zhurnal. № 1 . 2010. S. 56-60.

11. Kozbanenko V.A. Pravovoe obespechenie statusa gosudarstvennykh i munitsipal'nykh sluzhashchikh: obshchee i osobennoe. //Gosudarstvo i pravo. № 1. 2003. S. 13-24.

12. Konventsiya Organizatsii Ob"edinennykh Natsii protiv korruptsii (prinyata v g. N'yu-Iorke 31.10.2003 Rezolyutsiei 58/4 na 51-om plenarnom zasedanii 58-oi sessii General'noi Assamblei OON) // SZ RF. 2006. № 26. St. 2780

13. Manokhin B.M. Sluzhba i sluzhashchii v Rossiiskoi Federatsii: pravovoe regulirovanie. M.: Yurist, 1997. 294 s.

14. Postanovlenie administratsii Volgograda ot 30 avgusta 2011 g. № 2488 «0 sozdanii munitsipal'nogo kazennogo uchrezhdeniya «Material'no-khozyaistvennaya sluzhba» [Elektronnyi resurs].-Rezhim dostupa: Spravochno-pravovaya sistema «Konsul'tantPlyus».

15. Starilov Yu.N. Sluzhebnoe pravo. M.: BEK, 1996. $683 \mathrm{s.}$

16. Otdely administratsii Volgograda. Ofitsial'nyi sait administratsii Volgograda [Elektronnyi resurs].-Rezhim dostupa: http: // www.volgadmin.ru/ru/MPAuthority/Otdel.aspx

17. Ukaz Prezidenta RF ot 18 maya 2009 g. № 557 «Ob utverzhdenii perechnya dolzhnostei federal'noi gosudarstvennoi sluzhby, pri naznachenii na kotorye grazhdane i pri zameshchenii kotorykh federal'nye gosudarstvennye sluzhashchie obyazany predstavlyat' svedeniya o svoikh dokhodakh, ob imushchestve i obyazatel'stvakh imushchestvennogo kharaktera, a takzhe svedeniya o dokhodakh, ob imushchestve i obyazatel'stvakh imushchestvennogo kharaktera svoikh suprugi (supruga) i nesovershennoletnikh detei» // SZ RF. 2009. № 21. St. 2542.

18. Federal'nyi zakon ot 2 marta 2007 g. № 25-FZ «O munitsipal'noi sluzhbe v Rossiiskoi Federatsii» // SZ RF. 2007 . № 10. St. 1152.

19. Federal'nyi zakon ot 28 avgusta 1995 goda № $154-\mathrm{FZ} \mathrm{«Ob} \mathrm{obshchikh} \mathrm{printsipakh} \mathrm{organizatsii} \mathrm{mestnogo} \mathrm{samoupravleniya}$ v Rossiiskoi Federatsii» (utratil silu) // SZ RF. 1995. № 35. St. 3506.

20. Federal'nyi zakon ot 31 iyulya 1995 goda № $119-\mathrm{FZ}$ «Ob osnovakh gosudarstvennoi sluzhby Rossiiskoi Federatsii» (utratil silu) // SZ RF. 1995. № 31. St. 2990.

21. Federal'nyi zakon ot 6 oktyabrya 2003 g. № 131-FZ «Ob obshchikh printsipakh organizatsii mestnogo samoupravleniya v RF» // SZ RF. 2003. № 40. St. 3822.

22. Federal'nyi zakon ot 8 yanvarya 1998 g. № 8-FZ «Ob osnovakh munitsipal'noi sluzhby v Rossiiskoi Federatsii» (utratil silu) // SZ RF. 1998. № 2. St. 224.

23. Yusupov V.A. Nauchnaya organizatsiya ispolnitel'noi vlasti. Volgograd. Izd-vo Volgogr. in-ta ekonomiki, sotsiologii i prava, 1998. $147 \mathrm{~s}$. 